\title{
ANALISIS PENGELOLAAN MANAJEMEN LOGISTIK OBAT DI INSTALASI FARMASI RUMAH SAKIT QIM BATANG TAHUN 2021
}

\author{
Naela Afiya ${ }^{1}$, Yulian Wahyu Permadi ${ }^{* 2}$, St. Rahmatullah ${ }^{3}$, Wulan Agustin Ningrum ${ }^{4}$ \\ 1, 22,3,4 Program Studi Sarjana Farmasi Fakultas Ilmu Kesehatan Universitas Muhammadiyah Pekajangan \\ Pekalongan, Indonesia \\ e-mail: $\underline{1 \text { naelaafiya82@gmail.com, }} \frac{*^{2} \text { yulian_wahyu_permadi@yahoo.com, }}{{ }^{3} \text { amma88.an@gmail.com }}$,
}

\begin{abstract}
ABSTRAK
Pengelolaan obat merupakan rangkaian suatu kegiatan yang meliputi pemilihan, perencanaan, pengadaan, penerimaan, penyimpanan, pendistribusian pemusnahan, pengendalian dan administrasi. Pengelolaan obat sangat penting untuk menunjang pelayanan kesehatan pada pasien. Pengelolaan obat salah satu pendukung penting dalam pelayanan kesehatan hal ini perlu dilakukan agar dapat melakukan perbaikan kualitas dasar. Tujuan dari penelitian ini yaitu untuk mengetahui bagaimana pengelolaan manajemen logistik obat di instalasi farmasi Rumah Sakit QIM Kabupaten Batang. Metode yang digunakan adalah kualitatif. Pengumpulan data dilakukan dengan wawancara dan kuesioner. Jumlah sampel dalam penelitian ini yaitu 33 reponden. Berdasarkan hasil penelitian yang telah dilakukan pada manajemen pengeloaan obat di Rumah Sakit QIM proses pemilihan 93,9\% kategori sangat baik, perencanaa 90,9\% kategori baik, pengadaan 97,3\% kategori sangat baik, penerimaan 100\% kategori baik, penyimpanan 100\% kategori sangat baik, pengendalian 100\% kategori baik, pemusnahan 90,9\% kategori sangat baik dan administrai 100\% kategori sangat baik. Dari data yang diperoleh, peneliti dapat mengetahui terkait pengelolaan obat di Instalansi Farmasi Rumah Sakit QIM Batang.
\end{abstract}

Kata kunci: Analisis, Logistik Obat, Pengelolaan, Manajemen.

\begin{abstract}
Drug management is a series of activities that include selection, planning, procurement, receipt, storage, distribution, destruction, control and administration. Drug management is very important to support health services for patients. Drug management is one of the important supporters in health services, this needs to be done in order to improve basic quality. The purpose of this study is to find out how to manage drug logistics management at the pharmacy installation of QIM Batang Hospital. The method used is qualitative. Data was collected by means of interviews and questionnaires. In this study, 30 respondents distributed questionnaires. The number of samples in this study were 33 respondents. Based on the results of research that has been carried out on drug management at QIM Hospital, the selection process is $93.9 \%$ very good category, planning is $90.9 \%$ good category, procurement is $97.3 \%$ very good category, acceptance is $100 \%$ good category, $100 \%$ storage very good category, control $100 \%$ in good category, destruction $90.9 \%$ in very good category and $100 \%$ in very good category. From the data obtained, researchers can find out related to drug management at the Pharmacy Installation of QIM Batang Hospital.
\end{abstract}

Keywords: Analysis, Drug Logistics, Management, Management

\section{PENDAHULUAN}

Menurut Henni Febriawati [1], manajemen logistik merupakan bagian dari proses rantai pasok dan fungsinya yaitu merencanakan, melaksanakan dan mengendalikan efisiensi dan efektifitas arus penyimpanan barang, jasa dan informasi pelayanan dan informasi terkait dari tempat asal sampai ke tujuan, tempat produksi, konsumsi. Manajemen logistik merupakan bidang manajemen yang tugasnya khusus mengurusi logistik obat dan alat kesehatan dalam pelayanan kesehatan. Tujuannya adalah untuk memenuhi kebutuhan pelanggan. Untuk memberikan pelayanan pengobatan secara efektif dan efisien diperlukan sistem pengelolaan obat yang merupakan rangkaian suatu kegiatan mulai dari pemilihan hingga pencatatan dan pelaporan. Sistem penyimpanan obat merupakan suatu kegiatan yang dilakukan untuk melaksanakan keamanan obat- 
obatan serta perbekalan kesehatan yang diterima, untuk menjaga keamanannya, kualitas obat tetap terjamin dan agar terhindar dari kerusakan fisik maupun kimia. Pelayanan pengobatan merupakan salah satu komponen dasar yang dapat mendukung suatu pelayanan di rumah sakit [2].

Pemahaman terhadap Standar Pelayanan Kefarmasian di Rumah Sakit terkait pengelolaan sediaan farmasi yang beragam atau tidak tepat cenderung mengakibatkan masalah yang ujungnya adalah masuknya sediaan farmasi yang tidak memenuhi syarat ke rumah sakit yang mengancam keselamatan pasien. Demikian pula, dalam pelaksanaan pelayanan farmasi klinik, perbedaan pemahaman mengakibatkan beragamnya cakupan pelayanan serta ketidak jelasan dalam cakupan pelayanan yang lebih teknis. Dampak dari pengelolaan obat dalam rangka mencapai pelayanan yang bermutu maka perlu ditelusuri terlebih dahulu secara keseluruhan tahap-tahap bagaimana pengelolaan obat untuk mengetahui adanya permasalahan kelemahan dalam pelaksanaannya. Dalam hal ini mendorong peneliti untuk melakukan penelitian dan menganalisis pengelolaan obat pada tahap-tahap pemilihan, perencanaan, pengadaan, penerimaan, penyimpanan, pendistribusian dan pemusnahan di Instalasi Farmasi Rumah Sakit QIM Batang.

Instalasi Farmasi Rumah Sakit adalah salah satu bagian dari rumah sakit yang bertanggung jawab penuh atas pengelolaan obat serta faktor penting yang harus diperhatikan dalam memberikan pelayanan kesehatan yang merata kepada seluruh masyarakat di wilayah kerja rumah sakit dalam penyediaan obat-obatan yang dapat memenuhi kebutuhan pasien atau penderita [3].

Pengelolaan obat sangat penting untuk menunjang pelayanan kesehatan pada pasien. Pengelolaan obat salah satu pendukung penting dalam pelayanan kesehatan hal ini perlu dilakukan agar dapat melakukan perbaikan kualitas dasar. Menurut Henni Febriawatati [1], sistem distribusi obat meliputi penghantaran sediaan obat yang telah di dispensing instalasi farmasi ke daerah perawatan penderita dengan keamanan dan ketepatan jadwal, tanggal, waktu, metode pemberian obat kepada penderita serta keutuhan mutu obat.

Secara umum dalam sebuah rumah sakit, manajemen logistik adalah suatu penerapan prinsip-prinsip manajemen dalam kegiatan logistik dengan tujuan agar pergerakan personil dan barang dapat dilakukan secara efektif dan efisien. Manajemen logistik di rumah sakit merupakan salah satu aspek penting di rumah sakit. Ketersediaan obat di rumah sakit menjadi tuntutan pelayanan kesehatan. Manajemen obat di rumah sakit meliputi tahap-tahap yaitu perencanaan, pengadaan, penyimpanan, pendistribusian, penghapusan, evaluasi dan monitoring yang saling terkait satu sama lain, sehingga harus terkoordinasi dengan baik agar dapat berfungsi secara optimal [4].

Pelayanan kefarmasian bertanggung jawab atas pasien dan berkaitan dengan sediaan farmasi dengan tujuan agar meningkatkan mutu kesehatan pasien. Pelayanan kefarmasian didukung oleh adanya instalasi farmasi. Instalasi Farmasi Rumah Sakit (IFRS) adalah unit di rumah sakit yang bertanggung jawab penuh terhadap penggunaan obat yang efektif dan efisien [5]. Tujuan utama dari pengelolaan obat yaitu tersedianya obat dengan mutu yang baik, tersedia dalam jenis dan jumlah yang tepat sesuai dengan kebutuhan pelayanan kefarmasian bagi masyarakat yang membutuhkan [6].

\subsection{Alat dan Bahan}

\section{METODE PENELITIAN}

Alat yang digunakan pada penelitian ini yaitu berupa kuisioner. Pada penelitian ini dilakukan dengan pengambilan sampel dari Tenaga Kefarmasian di Instalasi Farmasi Rumah Sakit QIM Batang. Kuesioner merupakan suatu teknik pegumpulan data yang dilakukan dengan cara pengambilan memberi pertanyaan atau pernyataan tertulis kepada responden untuk menjawabnya [7]. Kuesioner yang akan dilakukan oleh peneliti yaitu jenis tertutup. Kuesioner tertutup merupakan kuesioner yang sudah disediakan jawaban dari peneliti sehingga reponden tinggal memilih. Penelitian ini dengan melakukan wawancara secara mendalam kepada Kepala Instalasi Farmasi Rumah Sakit, Kepala Penanggung Jawab Gudang di Rumah Sakit QIM Batang. Pada penelitian ini dilakukan dengan melakukan pengamatan langsung kepada informan. Pengumpulan data ini dilakukan dengan menggunakan alat ukur berupa kuesioner berskala Guttman, data yang telah diperoleh berupa data interval atau rasio dikotomi "Ya" dan "Tidak" sehingga dengan demikian 
penyusun berharap mendapatkan jawaban yang tegas terhadap suatu permasalahan yang diteliti.

\subsection{Jalannya}

Penelitian

\subsubsection{Uji Validitas dan Reabilitas}

Menurut Sugiyono [8], Validitas merupakan derajat ketepatan antara data sesungguhnya yang terjadi pada objek dengan data yang telah dikumpulkan oleh peneliti yang bertujuan untuk mencari validitas sebuah item. Dinyatakan valid jika koefisien antara item dengan total item diatas 0,3 , sebaliknya jika di bawah 0,3 maka dinyatakan tidak valid. Syarat minimum pada indeks valid yaitu $>0,3$, Oleh karena itu jika tingkat korelasi dibawah 0,3 maka harus diperbaiki karena dianggap tidak valid. uji validitas dilakukan dengan membagi kuesioner kepada 30 responden.

Menurut Sugiyono [7], uji realibilitas merupakan hasil pengukuran yang menggunakan objek yang sama akan menghasilkan data yang sama. Uji realibilitas dibagi menjadi dua kelompok yaitu kelompok item genap dan kelompok item ganjil. Masing-masing kelompok dijumlahkan agar menghasilkan skor total. Jika nilai korelasi 0,7 maka item tersebut memberikan tingkat reliabel, sebaliknya jika nilai korelasi dibawah 0,7 maka item tersebut tidak reliabel.

\subsubsection{Tahap pertama}

a. Tahap yang mencakup persiapan pembuatan proposal dan studi pendahuluan yang akan digunakan didalam penelitian

b. Kemudian pengajuan proposal serta permohonan ijin untuk melakukan penelitian yang akan diajukan kepada Program Studi Sarjana Farmasi Fakultas Ilmu Kesehatan Universitas Muhammadiyah Pekajangan Pekalongan

c. Tahap selanjutnya yaitu surat diajukan kepada Lembaga Teknis Daerah di Bidang Penelitian dan Perencanaan Pengembangan Daerah (BAPPEDA LITBANG) Kabupaten Batang untuk mendapatkan surat tembusan menuju Dinas Kesehatan Kabupaten Batang

d. Senlajutnya surat diajukan kepada Ketua Pergudangan Instalasi Farmasi Rumah Sakit QIM Batang untuk mendapatkan ijin melakukan penelitian sebagai prosedur resmi untuk melakukan penelitian terkait dengan pelaksanaan Analisis Pengelolaan Manajemen Logistik Obat di Instalasi Farmasi Rumah Sakit QIM Batang Tahun 2020.

\subsubsection{Tahap Kedua}

Tahap penulusuran dan pengambilan data yang dilakukan dengan menggunakan metode Quota Sampling. Dengan cara memberikan kuesioner kepada Ketua Pergudangan Instalasi Farmasi Rumah Sakit serta wawancara mendalam terkait dengan keadaan Gudang berdasarkan Standar Operasional Prosedur (SOP) pemilihan, perencanaan, pengadaan, penerimaan, penyimpanan, pendistribusian dan pemusnahan.

\subsubsection{Desain Penelitian}

Penelitian ini merupakan penelitian kualitatif yang menggunakan metode deskriptif. Penelitian kualitatif yaitu suatu prosedur penelitian sehingga menghasilkan data deskriptif berupa kata tertulis maupun lisan dari orang yang diamati. Tujuan dari penelitian ini yaitu agar dapat suatu informasi yang mendalam tentang objek yang diamati tentang sistem pengelolaan obat di Instalasi Farmasi Rumah Sakit QIM Kabupaten Batang. Pada penelitian ini dilakukan dengan pengamatan secara langsung yang disertai dengan wawancara kepada pihak yang terkait. Peneliti memberikan kuisioner kepada responden. Pada penelitian ini pengambilan sampel dengan menggunakan quota sampling, yaitu suatu 
teknik pengambilan sampel dengan cara mengambil jumlah yang sudah ditentukan oleh peneliti karena memiliki jumlah sampel yang terbatas.

\subsubsection{Tempat dan Waktu Penelitian}

Penelitian dilaksanakan di Instalasi Farmasi dan gudang farmasi Rumah Sakit QIM

Batang pada bulan Juli 2021.

\subsubsection{Populasi dan Sampel Penelitian}

Populasi yang digunakan dalam penelitian ini semua apoteker dan Tenaga Teknis Kefarmasian yang berjumlah 36 responden.

Sampel adalah sebagian anggota dari populasi yang dipilih sehingga diharapkan dapat mewakili populasinya. Jumlah sampel pada penelitian ini yaitu 33 responden.

\subsubsection{Cara Pengambilan Sampel}

Pengambilan sampel pada penelitian ini dilakukan dengan cara Quota Sampling. Quota Sampling merupakan suatu teknik yang digunakan untuk menentukan sampel dari populasi yang mempunyai ciri-ciri tertentu hingga jumlah yang diinginkan [9].

a. Kriteria inklusi

1) Tenaga kefarmasian dan Apoteker yang berada di Instalasi Farmasi Rumah Sakit

2) Tenaga kefarmasian dan Apoteker yang bersedia menjadi responden

3) Tenaga kefarmasian yang berpendidikan minimal D3

b. Kriteria Ekslusi

1) Tenaga kefarmasian dan Apoteker yang sedang cuti

2) Tenaga kefarmasian yang tidak bersedia menjadi responden.

\subsubsection{Variabel Penelitian}

Penelitian ini menggunakan variabel bebas dan variabel terikat. Variabel bebas pada penelitian ini yaitu Analisis Pengelolaan Manajemen Logistik Obat di Instalasi Farmasi Rumah Sakit QIM Batang. Sedangkan variabel terikatnya yaitu Kesesuaian Analisis Pengelolaan Manajemen Logistik Obat berdasarkan Petunjuk Teknis Standar Pelayanan Kefarmasian di Rumah Sakit Tahun 2019 di Rumah Sakit QIM Batang [10]

\subsection{Analisis Data}

Mengolah dan menghitung data yang diperoleh, kemudian menggunakan analisis persentase untuk menganalisis hasilnya secara deskriptif sebagai berikut.

Persentase $=\frac{\text { Jumlah skor perolehan }}{\text { Jumlah skor maksimal }} \times 100 \%$

Dimana : Nilai 1 untuk jawaban Ya

Nilai 0 untuk jawaban Tidak

\section{HASIL DAN PEMBAHASAN}

Pelaksanaan penelitian ini di Rumah Sakit QIM Batang. Dengan jumlah 33 responden, yang terdiri dari Tenaga Teknis Kefarmasian dan Apoteker. Metode dalam penelitian ini menggunakan metode deskriptif. Populasi dalam penelitian ini yaitu berjumlah 
36 responden tetapi hanya terkumpul 33 responden karena ada yang sedang melakukan cuti, dan ada yang sibuk tidak ada waktu untuk menjadi responden, karena kriteria inklusi skripsi ini tanaga kefarmasian yang berada di instalasi farmasi rumah sakit dan tenaga kefarmasian yang bersedia menjadi responden.

Pada penelitian ini yang pertama dilakukan uji validitas yang berfungsi untuk mengukur derajat ketepatan antara data sesungguhnya yang terjadi pada objek dengan data yang telah dikumpulkan oleh peneliti. Uji validitas menggunakan 30 responden, dari 90 pertanyaan terkait cara pengelolaan obat yang valid sebanyak 84 pernyataan dan yang tidak valid hanya 6 . Nilai $r$ tabel uji validitas yaitu 0,361 . Kemudian setelah melakukan uji validitas, dilakukan uji reliabilitas yang bertujuan untuk melihat apakah kuesioner memiliki konsistensi jika pengukuran dilakukan secara berulang setelah kuesioner dinyatakan valid. Syarat uji reliabilitas lebih dari 0,60 sedangkan nilai yang diperoleh sebesar 0,976 yang artinya reliabel, karena lebih dari 0,60 [11].

Tabel I. Hasil Kuesioner Pemilihan Obat di Instalasi Farmasi RS QIM Batang

\begin{tabular}{ccc}
\hline Kategori & Jumlah & Persentase (\%) \\
\hline Baik & 2 & 6,1 \\
Sangat Baik & 31 & 93,9 \\
Jumlah & 33 & 100 \\
\hline
\end{tabular}

Dari perolehan penelitian yang dilakukan di RS QIM Batang dengan jumlah total responden 33 bahwa 31 responden dengan perolehan 93,9\% mendapatkan kategori sangat baik dan 2 responden $(6,1 \%)$. Hasil penelitian ini menunjukkan persentase item obat berdasarkan Formularium Nasional sudah sesuai dengan standar. Hal ini disebabkan oleh kesadaran dokter dalam menggunakan obat sesuai Formularium Nasional di Rumah Sakit. Dibandingkan dengan penelitian kesesuaian obat dengan Formularium Nasional yang diteliti oleh Costa (2017) [12] sebesar 66,85\% di RSUD Ungaran Kabupaten Semarang Jawa Tengah. Menurut Kementrian Kesehatan bahwa nilai standar kesesuaian obat yang tersedia di IFRS dengan Fornas adalah $100 \%$ sebagai pedoman penyediaan item obat untuk BPJS di fasilitas kesehatan rumah sakit [13].

Tabel II. Hasil Kuesioner Proses Perencanaan Obat di Instalasi Farmasi RS QIM

\begin{tabular}{ccc} 
& Batang & \\
\hline Kategori & Jumlah & Persentase (\%) \\
\hline Baik & 3 & 9,1 \\
Sangat Baik & 30 & 90,9 \\
Jumlah & 33 & 100 \\
\hline
\end{tabular}

Hasil kuesioner proses perencanaan obat mendapatkan kategori sangat baik yaitu dengan perolehan 90,9\%. Namun sering terjadi kekosongan obat hal ini disebabkan oleh meningkatnya jumlah pasien karena pandemi dan kebanyakan dari pasien menggunakan pembayaran dengan kartu BPJS. Jadi pihak rumah sakit harus menunggu pencairan dana BPJS yang mengakibatkan tertunda melakukan pembayaran dengan supplier obat. Adapun pembelian obat secara online yang estimasinya ternyata tidak sesuai dengan perkiraan pihak IFRS. Proses perencanaan persediaan obat melibatkan Kepala Instalasi Farmasi dan Dokter. Adapun pedoman atau dasar yang digunakan dalam penyusunan perencanaan kebutuhan obat di instalasi rawat adalah formularium, kebutuhan obat dan pemakaian sebelumnya [14]. 
Tabel III. Hasil Kuesioner Proses Pengadaan Obat di Instalasi Farmasi RS QIM

Batang

\begin{tabular}{ccc}
\hline Kategori & Jumlah & Persentase (\%) \\
\hline Baik & 1 & 3,0 \\
Sangat Baik & 32 & 97,0 \\
Jumlah & 33 & 100
\end{tabular}

Hasil kuesioner proses pengadaan obat mendapatkan kategori sangat baik yaitu dengan perolehan $97,0 \%$. Menyatakan bahwa pengadaan obat dilakukan secara pembelian langsung kepada pihak distributor oleh salah satu petugas di ruang logistik. Pengadaan obat rumah sakit studi yang dilakukan yakni tidak hanya berdasarkan lembar perencanaan namun juga dapat dilakukan diluar hasil dari perencanaan obat yang sudah dilakukan. Jumlah obat yang dilakukan pengadaan diluar perencanaan berdasarkan dari adanya permintaan obat dari unit pelayanan atau depo namun tidak dapat dilayani oleh logistik farmasi rumah sakit

Tabel IV. Hasil Kuesioner Proses Penerimaan Obat di Instalansi Farmasi RS QIM

\begin{tabular}{ccc} 
& Batang & \\
\hline Kategori & Jumlah & Persentase (\%) \\
\hline Sangat Baik & 33 & 100 \\
Jumlah & 33 & 100 \\
\hline
\end{tabular}

Hasil kuesioner proses penerimaan obat mendapatkan kategori sangat baik yaitu dengan perolehan $100 \%$. Hal ini dikarenakan penerimaan obat yang diterapkan dapat menjamin spesifikasi obat, kesesuaian jenis, mutu, jumlah dan harga obat serta dokumen penerimaan obat disimpan dengan baik dan benar. Hal ini sesuai dengan hasil wawancara pada Kepala IFRS menyatakan bahwa instalasi farmasi selalu memeriksa obat yang diterima sesuai dengan slip penerimaan karena harus sesuai pesanan dan memastikan waktu kadaluarsa.

Tabel V. Hasil Kuesioner Proses Penyimpanan Obat di Instalasi Farmasi RS QIM Batang

\begin{tabular}{ccc}
\hline Kategori & Jumlah & Persentase (\%) \\
\hline Baik & 1 & 3,0 \\
Sangat Baik & 32 & 97,0 \\
Jumlah & 33 & 100
\end{tabular}

Dari perolehan penelitian hasil kuesioner proses penyimpanan obat mendapatkan bahwa 32 responden dengan perolehan 97,9\%. Hal ini sesuai dengan hasil wawancara dengan Kepala Instalasi Farmasi terkait penyimpanan obat menyatakan bahwa selalu memperhatikan kondisi seperti kelembapan, temperatur, cahaya agar menjamin mutu produk dan keamananmeyatakan bahwa sudah sesuai dengan Petunjuk Teknis Standar Pelayanan Kefarmasian di Rumah Sakit Tahun 2019 [10].

Tabel VI. Hasil Kuesioner Proses Pendistribusian Obat di Instalasi Farmasi RS QIM

\begin{tabular}{ccc} 
& \multicolumn{3}{c}{ Batang } \\
\hline Ketagori & Jumlah & Persentase (\%) \\
\hline Sangat Baik & 33 & 100
\end{tabular}


Dari perolehan penelitian hasil kuesioner proses pendistribusian obat yaitu dihasilkan dengan total 33 responden mendapatkan bahwa 33 responden dengan perolehan $100 \%$ mendapatkan kategori sangat baik dan sudah sesuai dengan standar. Hal ini sesuai dengan pernyataan wawancara dengan responden yaitu menyatakan bahwa gudang farmasi mendistribusikan ke unit pelayanan sesuai dengan permintaan.

Tabel VII. Hasil Kuesioner Proses Pemusnahan Dan Penarikan Obat di Instalasi Farmasi RS QIM Batang

\begin{tabular}{ccc}
\hline Ketagori & Jumlah & Persentase (\%) \\
\hline Baik & 3 & 9,1 \\
Sangat Baik & 30 & 90,9 \\
Jumlah & 33 & 100 \\
\hline
\end{tabular}

Dari perolehan penelitian hasil kuesioner dan wawancara pemusnahan dan penarikan dengan jumlah total respon 33 mendapatkan bahwa 30 responden dengan perolehan 90,9\% mendapatkan kategori sangat baik. Pemusnahan dan penarikan dilakukan sesuai dengan bentuk, jenis sediaan dan peraturan yang berlaku. Untuk pemusnahan psikotropika dan narkotika, dilakukan oleh apoteker dan disaksikan oleh dinas kesehatan kabupaten atau kota dan dibuat berita acara pemusnahan. Jika pemusnahan obat dilakukan oleh pihak ketiga maka instalasi farmasi harus memastikan bahwa obat telah dimusnahkan. Hasil dari wawancara pada Kepala IFRS menyatakan bahwa pemusnahan dilakukan apabila obat kadaluarsa. Penarikan dilakukan apabila ada produk recall, ada masalah ketika digunakan (biasanya alat kesehatan) dan obat yang mendekati kadaluwarsa ( 6 bulan sebelum kadaluarsa). Untuk obat kadaluwarsa yang menunggu waktu pemusnahan disimpan ditempat khusus. Pemusnahan narkotika dan psikotropika dilakukan bersama dengan Dinas Kesehatan dan sesuai dengan peraturan perundang-undangan yang berlaku.

Tabel VIII. Hasil Kuesioner Proses Pengendalian Obat di Instalansi Farmasi RS QIM

\begin{tabular}{ccc} 
& Batang & \\
\hline Ketagori & Jumlah & Persentase (\%) \\
\hline Sangat Baik & 33 & 100 \\
Jumlah & 33 & 100 \\
\hline
\end{tabular}

Dari perolehan penelitian yang dilakukan di RS QIM Batang dengan jumlah total respon 33 mendapatkan bahwa 33 responden dengan perolehan 100\% mendapatkan kategori sangat baik. Pengendalian yang sesuai yaitu penanganan ketika kadaluwarsa, penanganan ketika ada kerusakan, penanganan ketika menentukan stok optimum (stok obat yang diserahkan kepada unit pelayanan agar tidak mengalami kekosongan).

Tabel IX. Hasil Kuesioner Proses Administrasi Obat di Instalansi Farmasi RS QIM Batang

\begin{tabular}{ccc}
\hline Ketagori & Jumlah & Persentase (\%) \\
\hline Sangat Baik & 33 & 100 \\
Jumlah & 33 & 100 \\
\hline
\end{tabular}


Dari perolehan penelitian hasil kuesioner dan wawancara administrasi dengan jumlah total respon 33 mendapatkan bahwa 33 responden dengan perolehan 100\% mendapatkan kategori sangat baik. Administrasi yang sesuai yaitu memonitor transaksi sediaan farmasi yang masuk dan keluar di IFRS, jenis laporan yang wajib dibuat oleh IFRS meliputi laporan penggunaan psikotropika dan narkotika serta pelayanan kefarmasian, penerimaan dan pencatatan dilakukan secara rutin. Pencatatan keluar masuknya obat di gudang merupakan hal yang perlu dilakukan, dalam pencatatan keluar masuknya obat digudang Instalasi Farmasi RS QIM Batang dilakukan oleh masingmasing penanggung jawab gudang yaitu penanggung jawab gudang bagian administrasi gudang Berdasarkan hasil wawancara dengan Kepala IFRS menyatakan bahwa pencatatan dan pelaporan terhadap penerimaan dan penggunaan sediaan farmasi, alat kesehatan dan bahan medis habis pakai perencanaan dilakukan secara manual dan sistem untuk obat psikotropika dan narkotika ada yang harian dan bulanan.

\section{KESIMPULAN}

Hasil data yang diperoleh yang telah dilakukan di Rumah sakit QIM didapatkan bahwa Peneliti dapat mengetahui terkait manajemen pengelolaan obat di Instalansi Farmasi Rumah Sakit QIM Kabupaten Batang. Berdasarkan hasil data yang diperoleh yaitu dengan kuesioner dan wawancara kepada responden, manajemen pengelolaan obat di Instalansi Farmasi Rumah Sakit QIM Batang sesuai dengan petunjuk teknis standar pelayanan kefarmasian di Rumah Sakit Tahun 2019.

\section{DAFTAR PUSTAKA}

[1] Febriawati, Henni, "Manajemen Logistik Farmasi Rumah Sakit," 2013, Yogyakarta: Gosyen.

[2] DepKes RI, "Pedoman Pengelolaan Perbekalan Farmasi di Rumah Sakit", Direktorat Jendral Bina kefarmasian serta Alat Kesehatan, Kemenkes RI, 2010, Jakarta.

[3] Susanto, 2017. Evaluasi Penyimpanan dan Pendistribusian Obat di Gudang Instalasi Farmasi Rumah Sakit Advent Manado, Jurnal Ilmiah Farmasi Vol 6 no 4, 2017, [Online]

[4] Permenkes RI No.04 tahun 2018. "Kewajiban Rumah Sakit dan Kewaiban Pasien". Kementrian Kesehatan, 2018, Jakarta, [Online]

[5] Permenkes RI No.58 tahun 2014, "Standar Pelayanan Farmasi Rumah Sakit", Kementrian Kesehatan, 2014, Jakarta: Rineka Cipta, [Online]

[6] Quick D.J., Hume, M.L.O., Raukin J.R., Laing, RO., O’Conner RW, "Managing Drug Supply the Selection, Procurement, Distribution, and Use of Pharmaceutica", Second edition. Revised and Expaded, Kumarian Press, West Hartford, 2012, [Online]

[7] Sugiyono, "Metode Penelitian Kuantitatif, Kualitatif, dan R\&D", 2012, Alfabeta: Bandung.

[8] Sugiyono, "Metode Penelitian Kuantitatif, Kualitatif, dan R\&D", 2016, Alfabeta: Bandung.

[9] Sugiyono, "Metode Penelitian Kuantitatif, Kualitatif, dan R\&D", 2017, Alfabeta: Bandung.

[10] Petunjuk Teknis Standar Pelayanan Kefarmasian diRumah Sakit Tahun 2019.

[11] Wiratna, "Metodologi Penelitian", 2014, Yogyakarta: Pustaka Baru Press.

[12] Costa da Inacio, "Evaluasi pengelolaan obat di Instalasi Farmasi RSUD Ungaran Kabupaten Semarang Tahun 2016", Jawa Tengah, 2017, [Online]

[13] Permenkes RI No. 72 tahun 2016. Standar Pelayanan Kefarmasian di Rumah Sakit, [Online]

[14] Meity, dkk, "Analisis Pengelolaan Obat Di Instalasi Rawat Inap Rumah Sakit Jantung Bina". Jurnal Manajemen dan Administrasi Rumah Sakit Indonesia. Volume 3 No 2, 2019, [Online] 